\title{
CULTURA E CONSUMO: UMA DISCUSSÃO SOCIOANTROPOLÓGICA
}

\author{
CULTURA Y CONSUMO: UNA DISCUSSIÓN SOCIOANTROPOLÓGICA
}

CULTURE AND CONSUMPTION: A SOCIOANTHROPOLOGICAL DISCUSSION

\author{
Isabela Vicente MONTI ${ }^{1}$
}

RESUMO: O artigo objetiva efetuar uma revisão bibliográfica capaz de expor e explicar as principais categorias e conceitos desenvolvidos por estudiosos do fenômeno do consumo, a fim de evidenciar, em um primeiro momento, o pensamento antropológico desenvolvido por Marshall Sahlins acerca do porque os agentes sociais consomem, contrapondo-o com a visão utilitarista e, em um segundo momento, realizar uma discussão socioantropológica sobre o consumo através de uma síntese das contribuições de Jean Baudrillard, Mary Douglas, Pierre Bourdieu e Arjun Appadurai.

PALAVRAS-CHAVE: Consumo. Mercadorias. Antropologia.

RESUMEN: El artículo pretende hacer una revisión bibliográfica capaz de exponer y explicar las principales categorías y conceptos desarrollados por los estudiosos de lo fenómeno del consumo, con el fin de mostrar, al principio, el pensamiento antropológico desarrollado por Marshall Sahlins sobre por qué los agentes sociales consumen, contrastando con la visión utilitarista y, en un segundo momento, conduciendo una discusión socioantropológica sobre el consumo a través de una síntesis de las contribuciones de Jean Baudrillard, Mary Douglas, Pierre Bourdieu y Arjun Appadurai.

PALABRASCLAVE: Consumo. Mercancía. Antropología.

ABSTRACT: The article aims to carry out a bibliographic review capable of exposing and explaining the main categories and concepts developed by scholars of the phenomenon of consumption, in order to show, in a first moment, the anthropological thinking developed by Marshall Sahlins about why social agents consume, contrasting it with the utilitarian view and, in a second moment, conducting a socio-anthropological discussion on consumption through a synthesis of the contributions of Jean Baudrillard, Mary Douglas, Pierre Bourdieu and Arjun Appadurai.

KEYWORDS: Consumption. Merchandise. Anthropology.

${ }^{1}$ Universidade Estadual Paulista (UNESP), Araraquara - SP - Brasil. Graduanda em Ciências Sociais. ORCID: https://orcid.org/0000-0001-8904-3960. E-mail: isa.monti@terra.com.br 


\section{Introdução}

A relação entre cultura e consumo aparece enquanto uma temática relevante, no âmbito das ciências humanas e sociais, a partir do desfecho da segunda grande guerra mundial, intensificando-se nas décadas finais do século XX. Se, por um lado, as ciências sociais sempre atribuíram maior importância analítica para questões relacionadas ao trabalho, a produção e a racionalização no mundo moderno, por outro lado, a expansão da prática e do consumo, nas sociedades capitalistas ocidentais, estabeleceu a premência de formulações teóricas e conceituais acerca do sentido e significado do consumo e, também, dos bens materiais e mercadorias. Desse modo, o presente artigo objetiva efetuar uma revisão bibliográfica que apresente as categorias e conceitos desenvolvidos por estudiosos do fenômeno do consumo, a fim de evidenciar, em um primeiro momento, o pensamento antropológico desenvolvido por Marshall Sahlins acerca do porque os agentes sociais consomem, contrapondo-o com a visão utilitarista e, em um segundo momento, realizar um debate socioantropológico visando estabelecer uma síntese das contribuições de Jean Baudrillard, Mary Douglas, Pierre Bourdieu e Arjun Appadurai no debate contemporâneo sobre o tema.

O contexto em que o consumo passa a caracterizar um objeto de estudo para as ciências sociais alude ao que diversos autores denominaram por passagem da sociedade de produção para a sociedade de consumo (BAUMAN, 2001), no começo dos anos sessenta, quando houve um intenso processo de valorização da vida íntima e das experiências pessoais dos indivíduos, bem como a multiplicação de modelos e estilos de vida a serem seguidos, o que estabeleceu, por fim, aquilo que o filósofo político italiano Remo Bodei (2013) compreendeu como um "grande catálogo de vidas paralelas" possíveis de serem escolhidas e adquiridas. A busca pelo "verdadeiro eu", as preferências pessoais e a emotividade se transformaram em assuntos públicos, consolidando as forças do mercado que - nas sociedades capitalistas do Ocidente - passaram ofertar uma gama de serviços pessoais aos indivíduos.

Em um período de crescente flexibilização do capital e fim das utopias políticas compartilhadas, com o declínio das antigas geometrias políticas da primeira modernidade ${ }^{2}$, passamos para um tempo histórico em que as fantasias privadas e desejos particulares encontram-se em ascensão, aumentando a capacidade de diversificação do processo produtivo e gerando, consequentemente, uma variedade crescente de novas mercadorias.

${ }^{2}$ Compreendemos que a modernidade se constitui por diversas fases e formas. A primeira modernidade - século XVIII até a segunda metade do século XX - corresponde à sociedade industrial e nacional. 
Neste cenário inaudito, "o senso de valor pessoal não é mais apenas um problema de felicidade ou infelicidade privada, mas um problema público de justiça resumido pelo slogan "o pessoal é político" (EHRENBERG, 2012, p. 198). As décadas finais do século XX foram marcadas, também, por movimentos sociais que lutavam pelos direitos civis, afrodescendentes e pela libertação sexual, fazendo com que a igualdade de direitos fosse reconhecida conjuntamente com o valor pessoal dos indivíduos, consolidando uma série de novos estilos de vida a serem experimentados.

O período é característico, ainda, da consolidação da indústria de massa que, desde os anos 20, com o surgimento dos cinemas, disseminou novos modelos e padrões de comportamento, saúde, sexualidade e beleza, alterando o imaginário coletivo dos indivíduos. No que tange a esfera do consumo, Bauman (2008, p. 37) destaca o fato de que sempre se tratou de uma atividade humana trivial. Os seres humanos consomem todos os dias, "de modo prosaico, rotineiro, sem muito planejamento antecipado nem reconsiderações", o que configura uma característica de diversas formações sociais e em diferentes contextos culturais, políticos e econômicos. O consumismo - que ascende na segunda metade do século $\mathrm{XX}$ - no entanto, estaria relacionado ao fato do consumo assumir o protagonismo anteriormente atribuído ao trabalho, na sociedade dos produtores.

Partimos de uma sucinta caracterização do tempo histórico e espaço social em que emergem as discussões e pesquisas sobre o consumo para destacar que as sociedades contemporâneas apenas podem ser mais bem compreendidas mediante o estudo do mundo dos bens e de seus princípios de estruturação. Acreditamos que a antropologia, através do estudo dos significados culturais e, também da etnografia, possa contribuir proficuamente para um melhor entendimento das motivações, causas e consequências do ato de consumir, avançando no debate hodierno sobre o tema ao não dissociar, em sua interpretação de tal fenômeno, a dimensão econômica da atividade humana, da dimensão simbólica.

\section{Marshall Sahlins: utilidade ou razão simbólica?}

O pensamento desenvolvido, nos anos setenta, pelo antropólogo estadunidense Marshall Sahlins provocou uma inflexão, no interior do debate antropológico contemporâneo, ao propor uma teoria da história capaz de romper e superar as dicotomias usuais no interior das ciências humanas, como, por exemplo, aquelas de estrutura e história; estabilidade e mudança e sistema e evento. $\mathrm{O}$ autor, que fora influenciado pelo movimento conhecido como virada linguística - que atribuiu uma nova concepção à noção de signo e a de linguagem, que 
deixa de ser apreendida como aquilo que se insere no mundo apenas para nomear aos objetos, como se eles fossem coisas dadas, passando a ser assumida enquanto uma mediadora, constitutiva do mundo - estabeleceu, em sua obra intitulada Ilhas da História, que a história é ordenada culturalmente, em diferentes sociedades, de acordo com esquemas de significação das coisas, sendo o contrário também verdadeiro: esquemas culturais são ordenados historicamente porque os significados são reavaliados permanentemente quando realizados na prática.

Apesar das contribuições de Sahlins serem diversas no âmbito das ciências sociais, o presente artigo visa resgatar a obra Cultura e Razão prática em que o autor faz "uma crítica antropológica da ideia de que as culturas humanas são formuladas a partir da atividade prática e do interesse utilitário" (SAHLINS, 2003, p. 07) a fim de resgatar a maneira como a etnografia clássica estudou o consumo para, posteriormente, transpor a discussão para a antropologia contemporânea.

Contrapondo-se a noção utilitarista de que as relações humanas se restringem a mera maximização dos recursos e satisfação das necessidades e de que a cultura deriva da atividade puramente racional dos indivíduos na busca de interesses próprios e equações lógicas entre meios e fins, custos e benefícios - que consolidaram o que ficou conhecido no ocidente como razão prática, formal e instrumental -, o antropólogo norte-americano apresenta "uma razão de outra espécie: a simbólica ou significativa" (SAHLINS, 2003, p. 07). Esta forma de racionalidade não confere primazia ao fato de os homens viverem em um mundo material e, tampouco, estabelece que a qualidade decisiva da cultura é conformar-se as pressões da ordem material. O fato de os sujeitos históricos viverem de acordo com um esquema simbólico significativo, criado por eles próprios, é o que merece maior ênfase, segundo Sahlins.

Dando sequência em seu livro, o autor trava um debate teórico com o materialismo histórico que "ao tratar a produção como um processo natural e pragmático de satisfação de necessidades, corre o risco de se aliar com a economia burguesa no trabalho de aumentar a alienação dos indivíduos" (SAHLINS, 2003, p. 166). Sahlins ilustra que ao conceber a criação dos bens materiais somente a partir de suas quantidades pecuniárias - ou valor de troca - o materialismo histórico ignorou os códigos culturais de propriedades concretas que regem a "utilidade" (SAHLINS, 2003, p. 167), fomentando análises incompletas do fenômeno da produção. Nosso autor enfatiza que o valor de uso - dos bens - não pode ser definido no nível natural das necessidades e carências humanas, uma vez que as pessoas não produzem, por exemplo, meramente uma "habitação" - elas produzem tipos específicos de abrigos 
(SAHLINS, 2003, p. 169), ou seja, existe uma dimensão simbólica que caracteriza a forma de existência cultural e que é específica e intrínseca a cada sociedade. Entendemos, portanto, que o valor de uso é tão simbólico quanto o valor de troca.

É importante ressaltarmos que, por detrás da aparência de objetividade e praticidade, a economia - nas sociedades capitalistas ocidentais - é resultante dos significados que os sujeitos ativos atribuem a ela em seus esquemas culturais, sendo "[...] uma organização social das coisas, um projeto cultural de pessoas e bens" (SAHLINS, 2003, p. 167) sendo que toda produção material advém de uma intencionalidade cultural. Por isso, Sahlins assinala a impossibilidade de se compreender as sociedades ditas "tribais" com o aparato intelectual materialista histórico ou utilitarista. Isso se dá devido ao fato de que essas abordagens universalizam pressupostos culturais e econômicos que são válidos somente nas sociedades capitalistas do ocidente. Ao presumir que o valor de uso atenderia a todas as necessidades humanas, o próprio Marx ignorou o fato de que as necessidades humanas não são universais, mas sim relativas a cada esquema cultural.

Exemplificamos tal apontamento com uma breve descrição do ensaio Cosmologias do capitalismo: o setor transpacífico do sistema mundial, em que Sahlins aborda o comércio europeu, no século XVIII, que englobava a Inglaterra, a China, e as ilhas polinésias, a fim de demonstrar que a expansão do Ocidente e, consequentemente, a ocidentalização que atingiu diversas áreas geográficas e diferentes culturas não fora assimilada passivamente pelos povos nativos, mas fora ressignificada de acordo com as maneiras pelas quais as pessoas atribuíam sentido a existência através do simbólico (seus esquemas culturais e conjunto de códigos e signos culturais), caracterizando uma nova forma de ver a relação entre o global - que é constantemente ressignificado - pelo local.

Cosmologias do Capitalismo também ilustra como os esquemas culturais característicos de cada povo são os responsáveis por definir os valores e usos das coisas, ou seja, aquilo que é útil e valioso em determinado ordenamento social. Nesse sentido, o texto de Sahlins demonstra como os ingleses, na busca de obter o chá - proveniente da China - foram até as ilhas polinésias para a aquisição de sândalo, produto cobiçado pelos chineses, para conseguirem, por fim, negociar com o império chinês. Sahlins, ainda, retrata que entre a cosmologia chinesa e inglesa existem diferenças substanciais, dadas pelo conjunto de códigos culturais que orientam cada uma dessas sociedades.

Destacamos, assim, que a própria noção de "utilidade", tão cara aos economistas neoclássicos e utilitaristas, é um constructo valorizado e estabelecido por intermédio de esquemas culturais do ocidente. A vida social aparece, então, como um constante processo em 
que pessoas e objetos definem-se uns aos outros, sendo que toda a produção material deriva, primeiramente, de uma intenção cultural (SAHLINS, 2003). Segundo o autor:

O produto que chega ao seu mercado de destino constitui uma objetificação de uma categoria social e, assim ajuda a constituir esta última na sociedade; em contrapartida, a diferenciação da categoria aprofunda os recortes sociais do sistema de bens. O capitalismo não é pura racionalidade. É uma forma definida de ordem cultural (SAHLINS, 2003, p. 185).

O autor enfatiza que é a lógica simbólica - das diferentes culturas - que organiza a procura de bens de consumo, e não a quantidade ou qualidade material de tais bens. Para o antropólogo, o valor de troca é dado pelo significado cultural atribuído aos objetos, sendo que tais objetos são interpretados como meios de comunicação, em que a "[...] ordem cultural reflete a si própria na produção de objetos, estabelecendo, assim, uma "ordem de bens" (SAHLINS, 2003, p. 178).

\section{O debate socioantropológico contemporâneo sobre o consumo}

Ao analisar o fenômeno do consumo, nas sociedades contemporâneas, incluindo na francesa e na norte-americana, o sociólogo francês Jean Baudrillard (1929-2007) destaca a importância da dimensão simbólica na esfera econômica, criticando, assim como Sahlins, à razão prática e utilitarista que interpretava o ato de consumir - bens e mercadorias - como puramente racional, individual e atrelado a maximização de satisfações pessoais. Para o autor:

Pode-se conceber o consumo como uma modalidade característica de nossa civilização industrial, a condição de separá-la de uma vez por todas de sua concepção comum e corrente: a de um processo de satisfação de necessidades. O consumo não é esse modo passivo de absorção e de apropriação que se opõe ao modo ativo da produção para por em equilíbrio esquemas ingênuos de comportamento (e de alienação). Tem-se que afirmar claramente, desde o princípio, que o consumo é um modo ativo de relação (não apenas com os objetos, mas com a coletividade e o mundo), um modo de atividade sistemática e de resposta global na qual se funda nosso sistema cultural (BAUDRILLARD, 1969, p. 222, tradução nossa ${ }^{3}$ ).

Baudrillard, sob a ótica semiológica e com forte influência da filosofia de Roland Barthes e do estruturalismo, aponta para a existência "de uma espécie de evidência fantástica

3 "Em efecto, se puede concebir el consumo como una modalidad característica de nuestra civilización industrial, a condición de separarla de una vez por todas de su acepción común y corriente: la de um proceso de satisfacción de las necesidades. El consumo no es ese modo pasivo de absorción y de apropiación que oponemos al modo activo de la producción para poner em equilibrio esquemas ingenuos de comportamiento (y de alienación). Hay que afirmar claramente, desde el principio, que el consumo es un modo activo de relación (no solo con los objetos, sino com la colectividad y el mundo), un modo de actividad sistemática y de respuesta global em el cual se funda todo nuestro sistema cultural.” (BAUDRILLARD, 1969, p. 222). 
do consumo e da abundância, criada pela multiplicação dos objetos, dos serviços, bens materiais, originando como que uma categoria de mutação fundamental na ecologia da espécie humana" (BAUDRILLARD, 1995, p. 15). Entendendo a sociedade como um sistema de signos, o autor estuda o sistema de significados instaurados pelos objetos nos arranjos societários capitalistas. Para ele, os objetos constituem um sistema falado e possuem significados relacionais, definidos pelo contexto em que se inserem. Destacamos que o valor econômico das coisas é visto, também, como algo relacional. Em sua obra intitulada $\mathbf{O}$ sistema dos objetos, o sociólogo apreende que:

O consumo não é nem uma prática material, nem uma fenomenologia da abundância, não se define nem pelo alimento que se digere, nem pela roupa que se veste, nem pelo automóvel que alguém utiliza, nem pela substancia oral e visual das imagens e mensagens, mas sim pela organização de tudo isso em substancia significante. É a totalidade virtual de todos os objetos e mensagens constituídas desde agora em um discurso mais ou menos coerente. Enquanto tem um sentido, o consumo é uma manipulação sistemática de signos (BAUDRILLARD, 1969, p. 224, tradução nossa ${ }^{4}$ ).

Abordando o consumo sob uma perspectiva que vai além da "metafísica das necessidades e da abundância", Baudrillard (1995, p. 59) destaca que a verdadeira lógica social do consumo é a lógica da produção e manipulação de significantes sociais. Não se trata, portanto, da apropriação do valor de uso dos bens e tampouco da satisfação. Nesse sentido, entendemos que "nunca se consome o objeto em si (valor de uso) - os objetos manipulam-se sempre como signos que distinguem os indivíduos” (BAUDRILLARD, 1995, p. 60), agindo como reforçadores de vínculos, hierarquias e lugares sociais. Dessa maneira, o consumo não se refere mais aos objetos simplesmente, ele designa um conjunto de signos que possuem suas próprias funcionalidades, de modo que os objetos consumidos - enquanto signos - deixam de se relacionar com necessidades estabelecidas ou funções definidas, configurando-se de modo arbitrário e não coerentes com nenhuma relação concreta.

É importante ressaltarmos, ainda, que preocupado com a proliferação desses objetos de consumo em todas as esferas da vida humana, Baudrillard compreende que as mercadorias teriam se juntado aos signos, formando mercadorias-signo, que estariam se distanciando do real e concreto, passando a caracterizar, cada vez mais, a dimensão simbólica e não utilitária

4 "El consumo no es ni una práctica material, ni uma fenomenología, de la "abundancia", no se define ni por el alimento que se digiere, ni por la ropa que se viste, ni por el automóvil de que uno se vale, ni por la sustância oral y visual de las imágenes y de los mensajes, sino por la organización de todo esto en sustancia significante; es la totalidad virtual de todos los objetos y mensajes constituídos desde ahora en un discurso más o menos coherente. En cuanto que tiene un sentido, el consumo es una actividad de manipulación sistemática de signos." (BAUDRILLARD, 1969, p. 224). 
dos bens. Para o autor, nas sociedades de consumo os signos passam a caracterizar um excesso de significantes (ou seja, de formas e imagens) com pouca significação. Dizemos, portanto, que nos arranjos societários contemporâneos, encontramos um excesso e predominância de formas - de objetos, mercadorias - em detrimento dos conteúdos. O autor faz uma denúncia do capitalismo, alertando para um empobrecimento das relações humanas e significativas, evidenciando que o consumo age enquanto reforçador das lógicas do sistema.

Observamos, em uma breve síntese, que a denúncia da sociedade capitalista e do consumo estava presente, também, na teoria crítica frankfurtiana, fundamentalmente representada, em sua primeira geração, por pensadores como Max Horkheimer e Theodor Adorno. Possuindo forte influência do pensamento desenvolvido por Karl Marx, a teoria crítica opera de acordo com dois princípios: (1) a orientação para emancipação e (2) o comportamento crítico, e já no século XX, já apontava para os perigos da indústria cultural que, longe de significar uma cultura espontânea das massas, representava uma ideologia manifesta enquanto um conjunto de objetos confeccionados para atrair as massas em suas condições de consumidoras, adaptando e fixando seu estado de consciências, reificando todo o tecido social (HORKHEIMER; ADORNO, 1973). De modo tal que realidade e a aparência passaram a confundir-se em meio à dilatação da realidade tecnológica.

A antropóloga Mary Douglas, em sua obra conjunta com o economista Baron Isherwood, intitulada $\mathbf{O}$ mundo dos bens, estuda o fenômeno do consumo enquanto uma marca distintiva do espírito de nosso tempo, interpretando-o como parte constituinte da estrutura cultural das sociedades. A autora debruça-se sobre a tentativa de formular uma concepção universal de consumo, que não se limite apenas às sociedades capitalistas ocidentais.

De início, tal qual Baudrillard e Sahlins, Douglas (1994) distancia-se das concepções puramente econômicas e utilitárias do consumo, revisitando a noção clássica de que a escolha do consumidor é sua escolha livre, ainda que "[...] ele pode ser irracional, supersticioso, tradicionalista ou experimental: a essência do conceito de consumidor individual do economista é que ele exerce uma ação soberana" (DOUGLAS; ISHERWOOD, 2004, p. 101), que faz com que o consumo não seja imposto e, também, a noção de que o consumo começa onde/quando termina o mercado, que promove um consumidor privado e individual, a fim de evidenciar que, diferentemente do que afirmam estes pressupostos, as práticas de consumo partem de regras sociais e códigos culturais que fazem delas um ato público, porque coletivamente compartilhado. Enquanto fenômeno cultural, o consumo aparece como a apropriação de bens, espaços, serviços e práticas, que podem prescindir ou não da 
intermediação monetária. Mary Douglas define o consumo como uso ou apropriação de posses materiais que estão além do comércio e livre dentro da lei, o que permite que ele se consolide enquanto um conceito aplicável a outras sociedades que não somente as ocidentais.

A autora também efetua uma crítica da visão hedonista do consumo, que o explica como essencial para a realização pessoal e para a felicidade individual, interpretando-o como um reino do prazer através de um discurso altamente ideológico e difundido pela publicidade, que confere à posse infinita de bens o status de sucesso, fama e distinção. Douglas, ainda, se afasta da visão moralista do consumo, que o responsabiliza por uma extensa quantidade de problemas sociais, denunciando as desgraças familiares, econômicas, ecológicas e culturais das sociedades contemporâneas como conseqüências das práticas de consumo.

Everardo Rocha, na apresentação de $\mathbf{O}$ mundo dos bens ilustra que, no discurso moralista, a ideia do consumo aparece como "[...] objeto privilegiado de acusação - alienador como doença -, reforçando a superioridade moral da produção (de bens). Consumo não é para ser pensado, é para ser condenado como consumismo" (ROCHA, 2004, p. 12). Outro enquadramento recorrente utilizado na explicação do consumo é o naturalista, que o apreende como "biologicamente necessário, naturalmente inscrito e universalmente experimentado" (ROCHA, 2004, p. 14), avaliando o consumo através das respostas que ele dá as necessidades físicas dos indivíduos e pela satisfação dos desejos que ele propicia.

Com a finalidade de estabelecer e consolidar uma antropologia do consumo, Mary Douglas e Isherwood compreendem tal fenômeno como "a própria arena em que a cultura é objeto de lutas que lhe conferem forma" (DOUGLAS; ISHERWOOD, 2004, p. 103), enfatizando que devemos deixar de enxergar o consumo apenas como resultado objetivo do trabalho, reconhecendo- o como parte integrante do mesmo sistema social que explica as relações de trabalho, assim a autora sugere que:

Em vez de supor que os bens sejam em primeiro lugar necessários à subsistência e à exibição competitiva, suponhamos que sejam necessários para dar visibilidade e estabilidade às categorias da cultura. é prática etnográfica padrão supor que todas as posses materiais carreguem significação social e concentrar a parte principal na análise cultural em seu uso como comunicadores (DOUGLAS; ISHERWOOD, 2004, p. 105).

Enquanto comunicadores, os bens são necessários para dar visibilidade e estabilidade às categorias da cultura, agindo como parte de um sistema de significação, que supre necessidades, antes de tudo, simbólicas. Douglas e Isherwood (2004) aponta para o fato de que o principal problema da vida social é fixar os significados acordados, de modo que são os 
rituais que ajudam na contenção da variação e flutuação de significados sociais, agindo como convenções que delimitam definições públicas socialmente aceitas e praticadas.

Se, por um lado, "viver sem rituais é viver sem significados claros e, possivelmente, sem memória" (DOUGLAS; ISHERWOOD, 2004, p. 112), por outro lado, o consumo é entendido como um processo ritual que estabelece fronteiras simbólicas (cercas) e elos de pertença (pontes) entre os grupos sociais, servindo para fixar significados públicos e categorias e os bens de consumo, nessa perspectiva, são os acessórios rituais que atribuem sentido ao fluxo dos acontecimentos, possibilitando uma maior segurança no ordenamento social.

O consumo, como prática cultural e como processo ritual, se conecta a um sistema estrutural maior, cujos sentidos atribuídos aos bens vão muito além da categoria que se refere às trocas econômicas, sendo que os bens consumíveis e mercadorias qualificam marcos da existência coletiva no tempo, formando um sistema que atribui realidade a vida social. Mary Douglas, portanto, olha para o consumo não como uma função prática que visa atender necessidades práticas, mas como uma função simbólica, uma atividade ritual em que bens operam como comunicadores, repondo convicções, reforçando vínculos e estabelecendo, então, que as relações passam pelos objetos.

Longe de ignorar a dimensão do interesse mercantil inerente ao sistema capitalista com relação à prática e consumo de bens e mercadorias, a autora coloca um olhar microscópico que objetiva compreender os sentidos que as pessoas estão atribuindo à vida cotidiana e que, muitas vezes, escapa do crivo meramente mercantil. Quando se apreende que os objetos de consumo agem repondo convicções coletivas, reforçando vínculos, estabilizado significados e intermediando relações sociais, se constrói um arcabouço teórico e conceitual que permite entendermos, com mais profundidade, porque não é fácil combater o consumismo.

O sociólogo francês pós-estruturalista Pierre Bourdieu é um importante pensador que nos auxilia na compreensão de diversas questões sociais. Ao elaborar uma teoria capaz de dialogar com os três autores clássicos da sociologia: Emile Durkheim, Max Weber e Karl Marx, ele nos apresenta a necessidade da articulação, dialética, entre o ator social e as estruturas sociais, contribuindo com o debate socioantropológico ao inserir, em sua teoria, conceitos como o de campos sociais e habitus. Em sua obra intitulada Distinção: a crítica social do julgamento, ele realiza um estudo sobrea economia dos bens culturais de uma maneira que vai além de uma abordagem meramente econômica de tais bens, atribuindo a eles duas funções: a de sanar necessidades e a de estabelecer relações simbólicas. 
Contrapondo-se a visão do que chamou de "ideologia carismática", que considera os gostos como um dom da natureza, Bourdieu advoga que a observação científica demonstra que as necessidades culturais se caracterizam enquanto produto da educação, em que o nível de instrução de cada ator social se associa com suas preferências e práticas culturais. Desse modo, o autor enfatiza que o gosto e o olhar são socialmente construídos, servindo para manter - e legitimar - as desigualdades sociais. Nesse sentido, podemos compreender o gosto como sendo aquilo que classifica aquele que precede a classificação, sendo que os sujeitos sociais se diferenciam pelas distinções que eles próprios operam entre o belo e o feio, o certo e o errado, o apropriado e o inapropriado, e que acabam por se traduzirem na posição que esses sujeitos ocupam no interior das classificações objetivas (BOURDIEU, 2007).

Com isso, Bourdieu pretende elucidar que o gosto "legítimo" é dado pelo ator social dominante dentro de um determinado campo social - sendo o conceito de campo compreendido como um espaço social e simbólico constituído por agentes e instituições em constante disputa por legitimidade, onde a luta entre as classes sociais aparece como uma luta de classificação. Apreendemos, portanto, que "o gosto é o operador prático da transmutação das coisas em sinais distintos e distintivos, das distribuições contínuas em oposições descontinuas; ele faz com que as diferenças inscritas na ordem física dos corpos tenham acesso à ordem simbólica das distinções significantes”(BOURDIEU, 2007, p. 166).

Em uma breve síntese, nos é possível afirmar que uma das teses centrais presentes na obra a Distinção consiste na interpretação do consumo como uma estratégia distintiva. A partir disso, Bourdieu destaca que a classe dominante se distingue, das demais classes dominadas de seu campo social, a partir de "três estruturas de consumo distribuídas em três bens principais: alimentação, cultura e despesas com apresentação de si e com representação vestuário, cuidados de beleza, artigos de higiene" (BOURDIEU, 2007, p. 174), que demarcam a classe.

Evidencia-se que o acúmulo de determinados bens constitui-se enquanto um capital cultural e simbólico que não é encontrado em todos os indivíduos. As diferenças que os desiguais capitais culturais demarcam, são as responsáveis pela distinção de determinados grupos sociais, em detrimento de outros, bem como servem para promover identificações entre os iguais, contribuindo para a perpetuação do ordenamento social existente.

Apontamos, assim, para duas concepções do fenômeno do consumo, por um lado, apresentado enquanto um reforçador e reprodutor da lógica do sistema capitalista contemporâneo, denunciado na teoria crítica de Max Horkheimer e Theodor Adorno acerca da indústria cultural e, também, nas obras de Baudrillard e a proliferação das mercadorias-signo 
e, por outro lado, como uma prática cultural e ritual que codifica e ordena as diferentes sociedades, assim como também serve para distinguir os grupos sociais, legitimando posições e hierarquias entre diferentes indivíduos.

Outros importantes pensadores do âmbito das ciências sociais e humanas também se debruçaram sobre as práticas de consumo. Destacamos, brevemente, o pensamento do antropólogo Arjun Appadurai, que em sua obra intitulada A vida social das coisas, em confluência com o pensamento de Mary Douglas e Marshall Sahlins, estabelece que o consumo possui diversos sentidos além daquele que versa sobre uma racionalidade instrumental. $\mathrm{O}$ autor apresenta como proposta de estudo a discussão do raio de definição do conceito de mercadoria, através de uma articulação entre autores como Marcel Mauss, Karl Marx e Georg Simmel.

Appadurai destaca que as mercadorias podem ser "definidas provisoriamente como objetos de valor econômico" (1991, p. 17). Com a finalidade de fundamentar detalhadamente a definição de valor econômico, ele recorre à obra Filosofia do dinheiro, de Simmel, elucidando que para o sociólogo alemão "o valor nunca é uma propriedade inerente aos objetos, mas sim um juízo acerca deles emitido pelos sujeitos" (APPADURAI, 1991, p. 17). É interessante resgatarmos que:

Ao explorar este intrincado domínio, que não é totalmente subjetivo nem totalmente objetivo, onde o valor surge e funciona, Simmel sugere que os objetos não são difíceis de adquirir porque sejam valiosos, "senão que chamamos valiosos a esses objetos que se resistem contra nosso desejo de possuí-los". O que Simmel denomina objetos econômicos em particular, existe no espaço compreendido entre o desejo puro e o desfrute imediato, o qual implica certa distância entre eles e a pessoa que os deseja, distância que pode salvar-se. Esta distância se cobre em e através do intercâmbio econômico, onde o valor dos objetos está determinado reciprocamente. Quer dizer, o desejo de alguém por um objeto se alcança mediante o sacrifício de algum outro objeto, que é o centro do desejo de outro indivíduo (APPADURAI, 1991, p. 18).

Nos é possível apreender, portanto, que o que define o valor de um objeto econômico é a relação, a interação, o contexto que o engloba, bem como a esfera do sacrifício e da troca. $\mathrm{O}$ autor ilustra que os objetos econômicos circulam em diferentes regimes de valor em um dado tempo histórico e espaço social, de modo que a demanda por um bem de consumo, o sacrifício recíproco e o poder, interagem conjuntamente para criar o valor econômico, em situações sociais sempre específicas (APPADURAI, 1991).

Destarte, para ele, as coisas possuem - tal qual os seres humanos - uma vida social. Apontando para o fato de que, nas sociedades contemporâneas ocidentais, existe uma forte 
oposição entre as palavras e as coisas, em que se considera o mundo das coisas "como inerte e mudo, o qual é posto em movimento e animado apenas mediante as pessoas e as suas palavras" (1991, p. 19), Appadurai evidencia que:

\begin{abstract}
Apesar de que nosso próprio enfoque das coisas esteja necessariamente condicionado pela ideia de que as coisas não têm outros significados senão aqueles conferidos pelas transações, as atribuições e motivações humanas, o problema antropológico reside em que esta verdade formal não ilumina a circulação concreta, histórica, das coisas. Portanto, devemos seguir as coisas mesmas, já que seus significados estão inscritos em suas formas, usos e trajetórias. É apenas mediante a analise destas trajetórias que podemos interpretar as transações e cálculos humanos que animam as coisas (APPADURAI, 1991, p. 19).
\end{abstract}

Deste modo, é interessante pontuarmos que, se do ponto de vista teórico são os atores sociais que codificam a significação das coisas, de uma perspectiva metodológica são as próprias coisas que, em constante movimento, iluminam o contexto social e humano (APPADURAI, 1991). É possível apreendermos que, para Appadurai, ao seguirmos o caminho de circulação das coisas, iremos nos deparar com o fato de que seus respectivos significados se encontram no uso de que fazemos delas, e isso porque, para o autor, o valor de uso das coisas é simbólico, assim como o valor de troca. Destacamos ainda, que as coisas possuem uma biografia cultural.

Para os economistas, tradicionalmente, as mercadorias "simplesmente são", de sorte que "certas coisas e direitos sobre as coisas são produzidos, existem e circulam através do sistema econômico, enquanto são trocados por outras coisas, usualmente por dinheiro" (APPADURAI, 1991, p. 89), fazendo com que as mercadorias signifiquem apenas um artigo que possui valor de uso e valor de troca. Para Appadurai, no entanto, a produção de mercadorias pode ser interpretada como um processo cultural e cognitivo, “[...] onde as mercadorias não apenas devem se produzir materialmente como coisas, mas também devem estar marcadas culturalmente como um tipo particular de coisas" (APPADURAI, 1991, p. 89), de modo que exista uma economia moral das coisas, por detrás da aparência de objetividade da economia.

Resgatamos a ideia do antropólogo indiano de que o pensamento ocidental estaria enganado ao dar por certo que as coisas - objetos físicos e direitos sobre eles - representam o universo natural das mercadorias enquanto que as pessoas representariam seres individualizados e dotados de singularidades e especificidades, uma vez que, durante toda a trajetória do processo civilizatório humano, as pessoas foram - e podem ser mercantilizadas, tal qual os escravos o foram séculos atrás, e as mercadorias, por sua vez, 
podem assumir uma especificidade em sua existência que não parte de sua concepção como uma simples mercadoria. As mercadorias, assim, representam uma fase da vida dos bens econômicos, que pode assumir diversos outros significados ao longo de sua existência. Os bens, por sua vez, não são meros produtos dos sujeitos, eles são produtores, uma vez que as coisas possuem agencia.

Ressaltamos, ainda, que um salto distintivo apresentado na Vida social das coisas é a concepção de que as pessoas não consomem porque são reprodutoras de uma lógica social que os manipula a consumir, mas sim porque a prática do consumo pressupõe uma agência, uma escolha, uma maneira de situar-se no mundo, que confere prazer aqueles que consomem.

\section{Considerações finais}

Através do debate socioantropológico sobre o fenômeno do consumo nas sociedades contemporâneas, o presente artigo buscou demonstrar os nexos causais presentes entre o pensamento de Marshall Sahlins, Jean Baudrillard, Mary Douglas, Pierre Bourdieu e Arjun Appadurai. Destacamos, como uma primeira semelhança entre os autores, o fato de que todos compreendem os objetos de consumo como signos, códigos culturais, sistemas de significações e comunicadores, que atribuem ao ato de consumir uma dimensão simbólica e coletiva, e não meramente particular e individual. Os autores em questão também tecem críticas à razão prática e utilitarista que, usualmente, estava presente nos escritos da economia clássica e neoclássica sobre o consumo, reduzindo-o a uma simples satisfação de desejos e maximização de necessidades, ignorando, por completo, a sua dimensão simbólica, cultural e compartilhada por todo o arranjo societário.

Evidenciamos, ainda, que para além de uma contribuição crítica - aos moldes de Baudrillard e da teoria crítica frankfurtiana - ao consumo entendido enquanto reprodutor da lógica do sistema capitalista, autores como Mary Douglas e Bourdieu contribuem para enxergá-lo em sua maior complexidade, demarcando que as pessoas consumem para reforçar vínculos sociais, elos de pertencimento, códigos culturais e, também, para efetuarem distinções e hierarquizações. Appadurai, por sua vez, explicita que a mercadoria é uma fase da vida dos bens, e que o consumo, ao pressupor uma agencia dos sujeitos, é um ato prazeroso.

Acreditamos, finalmente, que os autores supracitados são de fundamental relevância, conceitual e teórica, para um entendimento mais aprofundado das sociedades capitalistas hodiernas, em que o fenômeno do consumo - o aumento do setor terciário, da oferta de 
serviços e bens - ainda é, muitas vezes, interpretado com base em enquadramentos moralistas, hedonistas e naturalistas.

\section{REFERÊNCIAS}

APPADURAI, A. La vida social de las cosas. México: Grijalbo, 1991.

BAUDRILLARD, J. A sociedade de consumo. Lisboa: Edições 70, 1995.

BAUDRILLARD, J. El sistema de los objetos. México: Siglo XXI, 1969.

BAUMAN, Z. Vidas para consumo: a transformação das pessoas em mercadorias. Rio de Janeiro: Jorge Zahar, 2008.

BAUMAN, Z. Modernidade líquida. Rio de Janeiro: Jorge Zahar, 2001.

BODEI, R. Immaginare altre vite. Realtà, progetti, desideri. Itália: Feltrinelli, 2013.

BOURDIEU, P. A distinção: crítica social do julgamento. São Paulo: Edusp, 2007.

DOUGLAS, M.; ISHERWOOD, B. O mundo dos bens: para uma antropologia do consumo. Rio de Janeiro: Editora UFRJ, 2004.

EHRENBERG, A. La società del disagio: Il mentale e Il sociale. Torino: Einaudi, 2012.

HORKHEIMER, M; ADORNO, T. Ideologia. In: HORKHEIMER, M; ADORNO, T (Orgs.). Temas básicos da sociologia. São Paulo: Cultrix, 1973.

SAHLINS, M. Cultura e razão prática. Rio de janeiro: Jorge Zahar, 2003.

SAHLINS, M. Ilhas da história. Rio de janeiro: Jorge Zahar, 1990.

SAHLINS, M. Cosmologias do Capitalismo: O Setor Trans-Pacífico do Sistema Mundial. In: Reunião Brasileira de Antropologia, 16., 1988, Campinas. Anais [...]. Campinas, SP, 1988. p. 47-10. 


\section{Como referenciar este artigo}

MONTI, Isabela Vicenti. Cultura e consumo: uma discussão socioantropológica. Rev. Sem Aspas, Araraquara, v. 8, n. 2, p. 276-291, jul./dez., 2019. e-ISSN: 2358-4238. DOI: https://doi.org/10.29373/sas.v8i2.13244

Submetido em: 22/10/2019

Aprovado em: 19/12/2019

Publicado em: 30/12/2019 